\title{
Apresentação do dossiê "História e Natureza: I Encontro Argentina-Brasil sobre estudos do século XVIII"
}

No mês de outubro de 2020 foi realizado o evento acadêmico "História e Natureza: I Encontro Argentina-Brasil sobre estudos do século XVIII”, organizado pela Associação Brasileira de Estudos do Século XVIII (ABES18) e pela Asociación Argentina de Estudios del Siglo XVIII (AAES18). Foram realizadas cinco sessões virtuais para celebrar o $250^{\circ}$ aniversário da publicação do Sistema da Natureza, do Barão d'Holbach, e da História das duas Índias do Abade Raynal. O evento reuniu especialistas do Brasil e da Argentina, e os trabalhos que constituem este dossiê foram elaborados a partir das apresentações deste I Encontro.

$\mathrm{O}$ evento foi marcado por um intenso e enriquecedor intercâmbio de ideais, propiciando um diálogo franco entre pesquisadores e pesquisadoras de ambos os países. A diversidade de perspectivas se fez evidente na variedade de tradições filosóficas abordadas no Encontro, agora refletidas neste dossiê. Por meio da revisão crítica de autores como Bayle, Hume e Mandeville, foram explorados elementos de suas filosofias menos conhecidos, desvelando o pensamento desses autores sob novas perspectivas. Nesse mesmo sentido, junto a outras apresentações que examinaram textos menos estudados de filósofos como Diderot ou Kant, foram analisadas as obras de filósofas ainda negligenciadas pela fortuna crítica moderna, como Émilie Du Châtelet e Olympe de Gouges, e obras feministas cuja autoria ainda não foi estabelecida (textos que poderiam, inclusive, ser fruto de uma obra coletiva), como é o caso do panfleto Ensaio em defesa do sexo feminino. Por fim, também foram trazidos à luz autores cujos sistemas e reflexões, embora de importância central para os que se dedicam a estudar a modernidade, ainda permanecem a ser explorados, caso de Fontenelle, Condillac e Lessing.

No Encontro também foram apresentados trabalhos que adotaram um procedimento comparativo, permitindo um debate sobre os vínculos estabelecidos entre distintas tradições nacionais, como a francesa, a alemã e a escocesa. Há também apresentações que buscaram evidenciar as repercussões e os diálogos (ou os possíveis benefícios que poderiam deles ser retirados) que a filosofia de autores modernos, como d'Holbach, entretém com a ciência atual ou contemporânea. Foram igualmente explorados distintos domínios do pensamento e da ação, não apenas filosóficos, mas fundados na interpretação de textos de religiosos ou relativos aos mitos, como acontece no caso de Meslier e Vico. Finalmente, outros trabalhos se propuseram a enfatizar a importância dos circuitos clandestinos de circulação das ideias no período e sua expressão.

O dossiê completo, produto das apresentações realizadas no I Encontro, foi dividido em dois volumes, cuja íntegra é formada pela parceria internacional estabelecida entre as revistas Siglo Dieciocho (AAES18) e Cadernos de Ética e Filosofia Politica (USP). Enquanto o volume da revista argentina disponibiliza os artigos dos pesquisadores e pesquisadoras brasileiros, a edição brasileira oferece ao público os trabalhos dos pesquisadores e pesquisadoras argentinos. Convidamos, portanto, os leitores e leitoras a visitarem ambas as publicações, para que tenham uma visão abrangente e um acesso integral aos frutos do evento. 
Das apresentações acima mencionadas, o presente volume dos Cadernos conta com os seguintes artigos: Fernando Bahr, "Cudworth, Bayle y Hume: sobre o ateísmo estratonista"; Adrián Ratto, "Virtude e voluptuosidade: a figura de Epicuro no Ensaio sobre os reinos de Clándio e Nero, e sobre os costumes e os escritos de Sêneca, de Diderot"; Natalia Zorrilla, "A liberdade como poder semovente em Émilie Du Châtelet: reflexões primeiras"; Leandro Guerrero, "Uma primeira aproximação ao An Essay in Defence of the Female Sex (1696): sua autoria, sua estrutura argumentativa e suas estratégias retóricas"; Ricardo Cattaneo, "Visões catastróficas e inspirações edificantes. Kant entre Bengel e Lessing"; Luciana Martínez, "Uma leitura da doutrina kantiana do gênio"; Esteban Ponce, "As reflexões de Diderot no artigo Encyclopédie. Crítica e representação no dicionário francês"; Manuel Tizziani, "Antigo regime, opressão e revolução. O lugar da história no Mémoire de Meslier".

Além do patrocínio realizado pela ABES XVIII e pela AAES XVIII, a reunião entre ambos os países foi possível graças ao apoio do Programa de Pós-Graduação em Filosofia da FFLCH-USP e das revistas Siglo Dieciocho e Cadernos de Ética e Filosofia Politica, que agora publicam os volumes complementares apresentados ao público. As revistas também registram o seu agradecimento aos professores e professoras coordenadores do evento: Fernando Bahr (CONICET, CIF-INEO, UNL), Maria das Graças de Souza (USP), María Susana Seguin (IHRIM, ENS-Lyon, Univ. Montpellier III, IUF) e Pedro Paulo Pimenta (USP). Esses apoios reforçam o compromisso e o fortalecimento de laços entre as instituições acadêmicas brasileiras e argentinas dedicadas aos estudos filosóficos da modernidade.

Finalmente, a essa edição em que é publicada o dossiê se agregam artigos variados, recebidos e aprovados nas últimas chamadas. Inclui-se no presente volume uma tradução de textos de Rousseau, bem como uma resenha do livro "John Locke político: a marca da tolerância", de Antônio Carlos dos Santos.

Desejamos a todas e a todos uma excelente leitura!

Adrián Ratto (Universidad de Buenos Aires-CONICET)

Dario Galvão (Universidade de São Paulo e Paris 1)

Natalia Zorrilla (Universidad de Buenos Aires-CONICET)

Thiago Vargas (Universidade de São Paulo)

Equipes dos Cadernos de Ética e Filosofia Política e da Siglo Dieciocho 